\title{
Correlation between early maladaptive schemas and violence against women among a representative sample from a Lebanese population: Results of a cross-sectional study
}

\section{Clara Rahme}

Universite Libanaise

Chadia Haddad

Hopital Psychiatrique de la Croix

Marwan Akel

Lebanese International University

Chloe Khoury

Universite Libanaise

Hala Obeid

Universite Paris 1 Pantheon-Sorbonne Departement des langues

Souheil Hallit ( $\square$ souheilhallit@hotmail.com )

Universite Saint-Esprit de Kaslik Faculte de Medicine et des Sciences Medicales https://orcid.org/00000001-6918-5689

\section{Sahar Obeid}

Hopital Psychiatrique de la Croix

Research article

Keywords: women, early maladaptive schemas, violence, physical, non-physical

Posted Date: January 23rd, 2020

DOI: https://doi.org/10.21203/rs.2.21667/v1

License: (9) This work is licensed under a Creative Commons Attribution 4.0 International License.

Read Full License 


\section{Abstract}

Objective: The study objectives were to trace a linkage between Early Maladaptive Schemas (EMS) and Violence against Women (VAW) in this specific Lebanese patriarchal context while undertaking this research on a larger scope of those Lebanese women who don't have a choice to act against Violence.

Methods: This is a cross-sectional study that was conducted on Lebanese women between September and December 2018. Participants enrolled in this study were from all of Lebanon's governorates and selected using an equitable representative sample.

Results: Being divorced (Beta=12.11), having a partner addicted to substance (Beta=9.64), to alcohol (Beta=5.03), to gambling (Beta=4.78), have a history of threats, violence, assaults and crimes (Beta=8.45), higher child physical abuse scale (Beta=1.58), higher child sexual abuse scale (Beta=3.77), higher child psychological abuse scale (Beta=0.25), higher Stressful life experiences (Beta=0.24), higher social isolation (Beta $=0.43$ ), higher emotional deprivation (Beta=0.42), higher subjugation (Beta=0.31) and higher failure (Beta=0.52) were significantly associated with greater partner physical and nonphysical abuse.

Conclusion: This current research suggests a positive correlation between violence against women and the activation of early maladaptive schemas.

\section{Introduction}

Violence against women (VAW) is the world's most prevalent yet least known abuse of human rights ${ }^{1}$. It has been present throughout history in various cultures. However, the knowledge of this phenomenon has evolved in the last decades, now considered to be detrimental to the victims and families' health and wellbeing ${ }^{2}$. The United Nations described VAW as "any act of gender-based violence that results in physical, sexual or mental damage or pain to women, including risks of such acts, manipulation or deprivation of liberty, whether in public or private" 3 . In light of this, global prevalence indicates that at least 1 in 3 (35\%) of women endured either physical and/or intimate partner abuse or sexual abuse during their lifetime ${ }^{3}$. More accurately, the findings of a research in El Salvador indicated that $54 \%$ of females reported experiencing some sort of abuse knowing that the most common form of abuse is psychological (41\%), followed by emotional (39\%), physical (22\%) and sexual (13\%) violence ${ }^{4}$. In the Lebanese context, according to previous research, $35 \%$ of a sample of 1,418 Lebanese women admitted to medical centers were victims of domestic violence, $66 \%$ of whom were subjected to serious physical violence ${ }^{5}$.

Young believed that violence can trigger Early Maladaptive Schemas (EMSs) described as "wide, dysfunctional and omnipresent patterns, full of memories and feelings about one's self and interactions with others, created in childhood or adolescence and evolved during one's lifetime" ${ }^{6}$. Cognitive literature addresses the role of cognitive vulnerabilities in the victimization of early negative experiences and 
subsequent problems. Consistently, children who have been hurt and mistreated in their family at an early age may later develop EMSs ${ }^{7}$. Then for the women who suffer violence, the structure of the schema seems to prepare them to accept their partner's use of violence against them ${ }^{8}$. Previous studies looked at the role of accepting violence as a mediating mechanism. When adolescents experience child abuse or witness that a parent is subjected to violence by an intimate partner, they may learn to expect and tolerate victimization in their own relationships. Tolerance of abuse helps to explain the connection between early maladaptive schemas and the risk of violence against women ${ }^{6}$.

Young and Brown categorized schemes in five categories: Disconnection or Rejection (the idea that one's needs for security, protection, stability, caring, empathy, sharing of emotions, appreciation, and respect will not be fulfilled in a predictable way), Impaired autonomy and performance (ideas about oneself and the environment which interfere with one's perceived capacity to distinguish, survive, work separately or execute correctly), Impaired limits (lack of inner boundaries, responsibility towards others, or orientation towards long-term goals), Other-directedness (excessive focus on other people's desires, emotions, and reactions at the cost of one's own requirements to obtain love and approval, retain one's feeling of belonging, or prevent retaliation), and Overvigilance/inhibition (excessive emphasis on either suppressing one's spontaneous emotions, impulses and decisions or facing strict, internalized laws and standards of performance and ethical behavior, often at the cost of satisfaction, self-expression, comfort, or health) ${ }^{9}$. These schemas function as a reference in the interpretation and resolution of data and are shaped by various interactions with the environment. They are established from early experiences and continue to be triggered throughout life by distinct occurrences that the individual unconsciously perceives as being identical with childhood traumatic events. For J.E. Young, "preserving the schemas would benefit from the need for cognitive continuity aimed at building a sustainable vision of oneself and the world, even if it is incorrect and faulty" ${ }^{10}$. However, the results of the Lebanese study have shown that women who are victims of intimate partner violence have a higher level of early maladaptive schema activation, in particular in the areas of rejection and disconnection, impaired autonomy and performance, overvigilance and inhibition ${ }^{11}$.

Another important factor that is found to be predicted for VAW is the women's attachment style. Attachment theory is a helpful framework for the analysis of intimate relationships and attachment styles have proved appropriate for Intimate Partner Violence (IPV) prediction. From this view, early adverse experiences are thought to lead to the creation of inner working models that influence perception, affect and behavior in distinct interactions throughout life. As expressions of these models of work, attachment styles were recognized: secure (low in both in anxiety and avoidance), fearful (high in both dimensions), preoccupied (high in anxiety and low in avoidance), and dismissive (low in anxiety and high in avoidance) ${ }^{12}$. A research undertaken by Hare and collaborators offers empirical evidence for the moderating role of attachment on particular childhood traumatic exposure (i.e. living with fathers who were physically abusive of their mothers) and the use of violence in subsequent adult relationships ${ }^{13}$. Furthermore, PTSD may develop in some individuals following a traumatic event, including experiences with IPV. PTSD symptoms include re-experience, prevention, adverse cognition and mood changes, and 
excitement. In 55-92 \% of women with a history of IPV, high levels of PTSD symptoms have been found ${ }^{14}$.Although we can find few researches in Lebanon attacking the Early Maladaptive Schemas (EMS) ${ }^{11}$, however this specific correlation between EMS and VAW is not yet treated in the Lebanese context that is defined by being a patriarchal one.

VAW in Lebanon is not only rooted in the patriarchal society but is also encouraged by religion and culture from the belief that women belong to men ${ }^{15}$. As part of this patriarchal culture, masculinity is related to aggressiveness and violence which leads to the emergence of new forms of violence against the most vulnerable: women ${ }^{16}$. This traces well the main interest of this specific study in the Lebanese framework and its patriarchal society.

Finally, the aim of this study is to trace a linkage between Early Maladaptive Schemas (EMS) and Violence against Women (VAW) in this specific Lebanese patriarchal context while undertaking this research on a larger scope of those Lebanese women who don't have a choice to act against violence.

\section{Methods}

\section{Study design}

This is a cross-sectional study that was conducted on Lebanese women between September and December 2018. Participants enrolled in this study were from all Lebanese governorates and selected using an equitable representative sample. The governorates are divided into Caza (stratum), divided into villages. We nominated two villages from a list provided by the Central Statistics Agency in Lebanon, where we randomly picked the participants ${ }^{17}$. Women were excluded whether: (1) the questionnaire information were unfinished; (2) the woman declined to participate in the study; and (3) a psychiatric disorder was self-reported. Our study therefore included all other women who were 18 years of age and older and who did not meet one of the criteria for exclusion.

\section{Minimal sample size calculation}

We fixed our expected frequency of violence against women among the general population at $35 \%$ based on a previous study ${ }^{18}$. The Epi-info software version 7.2 (population survey) calculated a minimum sample size of 350 participants to ensure a confidence level of $95 \%$.

\section{Questionnaire}

During the interview, the questionnaire used was in Lebanon's native language, Arabic. The questionnaire was formed by many sections: the first section assessed the socio-demographic details of the participants (age, gender, marital status, educational level, income, etc.) while in the second section, Partner abuse scale (physical and non-physical), child abuse self-report scale, relationship questionnaire and PTSD checklist questionnaires were used. 


\section{Socio-demographic data}

In this part of the questionnaire, participants were asked about their age, educational level, income, marital and employment status to estimate the association of these socio-demographic features with the violence against women (VAW) ${ }^{19}$. Education has been classified as having attained the lowest to the highest level of education, the same for income. Marital status was registered as $1=$ single, $2=$ married, 3 = widowed, and 4 = divorced. Likewise, participants were asked about many factors that could pose a risk for the violence such as gambling partner, addicted partner (alcohol and drugs) and whether they are willing to also tell the police, whether they believe their partner have the right to beat them, whether they think that the divorce is shameful. These variables were dichotomized as $0=$ no and $1=$ yes.

\section{Early maladaptive schemas (EMS)}

The tool used in this research was the third edition of Young's schema questionnaire that analyzes 18 elements of the early maladaptive schema. This questionnaire comprises 90 items for each of the domains separated into five categories. They are rated from 1 to 6 as follows $(1=$ completely wrong, $6=$ describes me perfectly).

The schemas would be divided into five fields:

- Early patterns of disconnection and rejection: patterns of abandonment/instability, mistrust/abuse, emotional deprivation, defectiveness, and social isolation.

- Early patterns of impaired autonomy and/or performance: patterns of dependence, vulnerability to harm, enmeshment, and failure.

- Patterns of impaired limits: patterns of entitlement/grandiosity, and insufficient self-control.

- Early schemas of other-directedness: patterns of subjugation, self-sacrifice, and approval seeking.

- Early schemas of overvigilance/inhibition: patterns of negativity/pessimism, emotional inhibition, unrelenting standards, and punitiveness.

The score acquired on the subscales ranges between 5 and 30 because each subscale consists of 5 items. High average implies hyperactivation of the schema. This led to five levels for each schema, where degree $0=$ no schema, degree $0.2=$ there is only one item on the schema coted 5 or 6 , degree $0.4=$ presence of two schema-related items coted 5 or 6 , degree $0.6=$ presence of three schema-related items coted 5 or 6 , degree $0.8=$ presence of four schema-related items coted 5 or 6 , degree 1 presence of five schema-related items coted 5 or 6 . The higher the average, the more the schemes are dysfunctional. (Cronbach's alpha=0.964).

\section{Partner abuse scale - physical and nonphysical (PASP \& PASNP)}

These two 25 -item scales measure the perceived physical or non-physical abuse from an intimate partner, based on the abuser's self-report ${ }^{20}$. The physical abuse scale contains items about physical and forced sexual assault (i.e. my partner physically forces me to have sex ...). The non-physical abuse of partner 
scales items reflect psychological abuse or coercive behavior (i.e. my partner belittles me ...). Both questionnaires are scored based on a Likert's seven-point scale (1-7) as follows: Never (1), seldom (2), sometimes (3), usually (4), often (5), frequently (6), and always (7), with total scores ranging from 0 to 100 (high scores indicating more abuse) ${ }^{21,22}$. The Cronbach alpha values for each subscale were as follows: physical (0.983) and non-physical (0.979).

\section{Child abuse self-report scale (CASRS)}

This scale treated 38 items approved for the validity of content. The CASRS was divided into four categories of child abuse and neglect: psychological (14 items), neglect (11 items), physical (8 items) and sexual abuse ( 5 items). The format of the scale was based on a Likert style: $0=$ Never $1=$ Sometimes $2=$ Most often $3=$ Always $^{23}$. No abuse or neglect of responses is given a score of " 0 " and a score of " 3 " is given for severe abuse or neglect. Since the number of items in each subtest is different, users calculate the mean of each subtest; hence the scores for the test and the range of each subtest from 0 - 3 . High scores will show more childhood abuse ${ }^{24}$. The Cronbach alpha values for each subscale were as follows: psychological (0.950), neglect (0.940), physical (0.934) and sexual (0.871).

\section{Relationship questionnaire (RQ)}

The RQ consists of four short paragraphs, each paragraph describes one of the four adult attachment styles. Style A corresponds to the secure attachment, Style B to the preoccupied attachment, Style C to the fearful attachment and Style $D$ to the dismissing attachment. Each paragraph is rated on a 7 points scale $\left(1=\right.$ strongly disagree to $7=$ strongly agree) ${ }^{25}$. Higher scores would indicate a higher attachment of the selected style; for example, high secure attachment would be shown by a score 7 for style $A$.

\section{PTSD checklist - Civilian version (PCL-C):}

The PCL-C is a summated rating scale that gives a continuous measure of PTSD symptom severity with scores ranging from 17 to 85 . Participants are asked how much of a 5-point scale (ranging from $1=$ not at all to $5=$ extremely) they have been distressed by each PTSD symptom over the past month. A higher score suggests more severe symptoms of PTSD. Moreover, the PLC may also be scored to provide a constant measure for the three clusters of PTSD symptoms: re-experiencing (ranging from 5 to 25), avoidance (ranging from 7 to 35), and hyper-arousal (ranging from 5 to 25) (Cronbach's alpha=0.921).

\section{Statistical analysis}

The SPSS software version 23 was used to conduct data analysis. A Cronbach's alpha was recorded for reliability analysis for all the scales. A descriptive analysis were done using the absolute frequency and percentages for categorical variables and mean and standard deviation for quantitative measures. The Student t-test was used to compare continuous variables in two groups. Pearson correlation was used for linear correlation between continuous variables. For categorical variables, the chi-square and Fisher exact tests were used. Two stepwise linear regressions were conducted, taking the physical abuse scale and 
partner nonphysical abuse scale as the dependent variable. All variables that showed a $p<0.1$ in the bivariate analysis were considered as important variables to be entered in the model in order to eliminate the potential confounding factors. The stepwise method was used to simultaneously remove variables that were weakly correlated to the dependent variable. Thus, the final variables kept in the model explain better the distribution. A p-value less than 0.05 was considered significant.

\section{Results}

The sociodemographic characteristics of the participants are summarized in Table 1. The results showed that the mean age of the participants was $31.46 \pm 10.97$ years and the mean number of kids was $2.72 \pm$ 1.53. More than half of the participants were married (57.7\%) and had a university level of education (58.5\%), 63.2\% had low income, $42.8 \%$ were employed and 78.3\% were Muslims. Only $3.6 \%$ take substances and $19.8 \%$ drink alcohol.

\section{Bivariate analysis}

A higher mean of partner physical abuse scale was found in illiterate, divorced, non-employed, being an atheist compared to high educated, married, employed and being a Muslim participants. Also, a higher mean of partner physical abuse scale was found in alcohol and substance users, having a partner that have an history of threats, taking substance and addicted to alcohol as compared to those who do not have these behaviors. In addition, higher stressful life experiences, higher child (psychological, physical, neglect and sexual) abuse, higher preoccupied relationship style, higher fearful relationship style were associated with higher partner physical abuse scale whereas higher secured relationship style was associated with lower partner physical abuse scale. A higher mean of partner physical abuse scale was found in these early maladaptive schemas: emotional deprivation, abandonment, mistrust/abuse, social isolation, defectiveness, failure, higher dependence, higher vulnerability, higher enmeshment, higher subjugation, self-sacrifice, higher emotional inhibition, higher entitlement, higher approval seeking, higher negativity/pessimism and punitiveness.

A higher mean of partner nonphysical abuse scale was found in illiterate, divorced, non-employed, atheist compared to high educated, single, student and Muslims participants. Also, a higher mean of partner nonphysical abuse scale was found in alcohol and substance users, having a partner that have a history of threats, take substance and addicted to alcohol as compared to those who do not have these behaviors. In addition, higher age, higher stressful life experiences, higher child (psychological, physical, neglect and sexual) abuse, higher preoccupied relationship style, higher fearful relationship style were associated with higher partner nonphysical abuse scale whereas higher secured relationship style was associated with lower partner nonphysical abuse scale. A higher mean of partner nonphysical abuse scale was found in these early maladaptive schemas: emotional deprivation, abandonment, mistrust/abuse, social isolation, defectiveness, failure, dependence, vulnerability, enmeshment, subjugation, self-sacrifice, emotional inhibition, unrelenting, entitlement, approval seeking, negativity/pessimism and punitiveness. 


\section{Multivariable analysis}

The first linear regression taking the partner physical abuse scale as the dependent variables showed, that divorced, having a partner that take substance, addicted to alcohol, addicted to gambling, have a history of threats, violence, assaults and crimes were associated with higher partner physical abuse scale. Higher child (psychological, physical and sexual) physical abuse, higher stressful life experiences were associated with higher partner physical abuse scale. A higher mean of partner physical abuse scale was found in these early maladaptive schemas: defectiveness, approval seeking, social isolation, emotional deprivation, subjugation, failure and dependence. Having a university degree was associated with lower partner physical abuse scale.

The second linear regression taking the partner nonphysical abuse scale as the dependent variables showed, that married, widowed and divorced participants, having a partner addicted to gambling and to alcohol, and have a history of threats, violence, assaults and crimes were associated with higher partner nonphysical abuse scale. Higher preoccupied relationship style, higher child (physical, sexual and psychological) abuse, higher stressful life experiences were associated with higher partner nonphysical abuse scale. A higher mean of partner nonphysical abuse scale was found in these early maladaptive schemas: social isolation, subjugation, emotional deprivation and unrelenting standards. Having a university education level was associated with lower partner nonphysical abuse scale.

\section{Discussion}

Young stated that the maladaptive schemes stay silent until they are activated by an external act. Owing to this fact, an answer to the cognitive model is that the violence against women would result in the activation of dysfunctional schemes within them ${ }^{8}$. The results of the present study showed that women victims of both physical and non-physical violence show a higher level of activation of early maladaptive schemas. This is in line with an earlier research in Iran that revealed a close relationship between all fields of women's early maladaptive schemes and the extent of domestic violence against them ${ }^{8}$.

EMSs occur in early childhood or adolescence when basic emotional needs are not met in main interactions. They serve as reality-based representations of the surroundings of the individual. Although not all EMSs are products of maltreatment, they are reliably damaging and caused by deleterious events that constantly repeat themselves during childhood and adolescence ${ }^{26}$. According to Cottraux, childhood exposure to domestic violence improves the probability of violent intimate interactions in adulthood. A child, having a background of domestic violence, grows up in an insecure environment ${ }^{10}$.

There are several schema domains according to the model, depending on the need of the child that caregivers have not properly satisfied ${ }^{8}$. They can incorporate the use of violent behavior as a means of conflict resolution and trap the topic in a victim and/or perpetrator situation ${ }^{10}$. Due to the human need for consistency, maladaptive schemes fight for survival. In fact, in an effort to cope with their schemes and prevent the adverse feelings they produce, individuals embrace inappropriate coping styles that 
brings to the schemes ' perpetuation ${ }^{6}$. For this purpose, individuals with self-damaging models are engaged in interactions, circumstances and inattentive decisions that stimulate and stabilize the schema and prevent interactions that lead to schema regeneration ${ }^{8}$.

Among the eighteen schemas, eight schemas were associated with violence against women. The best domains relevant to victimization are the disconnection/rejection and the impaired autonomy domains. An earlier research conducted by Estevez et al revealed a positive association between VAW and the 5 EMSs with higher rations of the disconnection/rejection and the impaired autonomy domains ${ }^{9,11}$. The disconnection/rejection domain involves schemes which indicate that one's safety, empathy, nurturance, recognition and respect needs will not be met ${ }^{27}$. Three schemas were found to be associated with violence: first, the emotional deprivation schema in which a women sense that other individuals are unable to provide the love and care she needs, may join cold and abusive individuals with little affection; the second one is the defectiveness schema in which a women have expectations of being rejected and abused by others could result in women appearing weak and becoming a more probable target of abuse in intimate relations; the third one is social isolation schema in which a women feel isolated from other people ${ }^{6}$. The disconnection and rejection domain can explain some of the alterations in psychological and physical violence from the domestic violence aspects ${ }^{8}$. In this way, it is suggested by Calvete et al that childhood victimization contributes to the growth of schemes of this domain and, in turn, increases the likelihood of future victimization because schemes can be perpetuated by choosing abusive partners, targeting abusive partners or remaining in abusive relationships ${ }^{6}$.

In addition, impaired autonomy schemas can explain domestic violence considerably and can predict the amount of violence against women ${ }^{11}$. The impaired autonomy and performance domain involves schemes that involve an adverse perspective of one's capacity to succeed or operate independently of others ${ }^{27}$. Two schemas were found correlated under this domain: The failure scheme in which women who are abused have a damaged concept of themselves, their self-esteem can become extremely negative, increasing thus the risk of activating this scheme. Also, the dependency scheme in which women find themselves helpless and unable to manage their own circumstances ${ }^{10}$. Authors such as Barnett have observed that when a victim suffers from their partner's extended experience of abuse, their ideas about themselves and self-esteem may become highly negative, increasing the danger of depression ${ }^{9}$. Abused women, whose schemes are in this domain, are relying economically on their husbands which leads them to feel deprived of that personal source needed to fix the issue and operate separately ${ }^{11}$. Based on this context, a previous study stated that there is a link between abuse of one's own spouse and some of the special schemes of impaired autonomy and function, such as low selfefficacy, which limits the ability of individuals to break off the violent relationship ${ }^{8}$.

We found two schemas under the other-directedness domain was correlated with IPV: The subjugation schema in which the abused women becomes concerned with their partner's needs and desires by avoiding anything that can lead to an outburst for the controlling person ${ }^{28}$; The approval seeking 
schema in which women desire to gain approval, attention from her husband at the cost of creating a secure and true sense of self ${ }^{29}$.

And the last schema was the unrelenting standards schema under the domain of overvigilance and inhibition in which women have to strive continuously to fulfill elevated internalized behavioral norms. They face intense pressure to perform well, leading to intense anxiety about the likelihood of not living up to their internalized norms ${ }^{30}$. These 3 schemes are connected with VAW, but to our knowledge this association has not been studied by any prior research. Further studies are needed in this light to evaluate this association and assess the role of these schemes in violence against women.

Furthermore, we cannot disregard the context in which women are abused. This context involves patriarchal attitudes about women's inferiority and men's right to guide women. Traditional gender beliefs could generate the situation where it would be easier for women to incorporate maladaptive schemes composed of negative self-worth and expectations of abuse. Cultural elements such as gender roles and women's inferiority in culture could therefore make women more susceptible to developing maladaptive schemes when subjected to violence ${ }^{6}$.

On top of that, the background, education, family and socio-cultural environment in which an individual grew up distinguishes each partner. All of these factors introduce many aspects affecting these essential choices of life, especially the choice of a partner ${ }^{10}$. Some studies have been investigating the connection between VAW and impulsive behaviors such as substance abuse, alcohol abuse and gambling. A research in Iran showed that there was a considerably greater rate of violence among women with addicted spouses than among women with non-addicted spouses. Impulsivity, instability, bad selfesteem and lack of problem-solving abilities are the defining features of people attempting to intimidate their wives. These characteristics are significantly greater among addicts and then the level of violence in their homes would increase ${ }^{31}$. Our findings also proposed that low levels of violence are associated with high level of education and this is in line with previous literature. Women with higher education were more likely to be more independent and probably did not accept the mistreatment of their partners ${ }^{7}$.

We also discovered that high non-physical violence is associated with having a preoccupied attachment style. This is in line with prior research, which revealed that people involved with an adverse self-model actively seek permission from others to validate their fragile feeling of self-worth and are expected to experience elevated rates of anger in close relationships and subsequently violence ${ }^{32}$.

High levels of physical and non-physical violence was found correlated with high level of PTSD. This is consistent with prior research suggesting a sevenfold rise in the probability of PTSD among women experiencing violence and abuse ${ }^{33}$. PTSD is associated with a low level of optimism, an important factor that is known to serve both as a barrier against negative influences of violence and as a survival enhancer. Another possible explanation can be found in the PTSD-typical negative self-assessments observed among traumatized victims of violence. Negative self-assessment can be seen in poor maintenance of health and poor prevention of abusive behaviors ${ }^{34}$. 


\section{Clinical implications}

Despite the limitations, this research disclosed significant results that encouraged further exploration of early maladaptive schemes in battered women. And identifying the factors that enhance the activation of these schemes will assist to treat these schemes and mitigate their impacts. Further studies might therefore assist to better comprehend these schemes and thus better comprehend how they are connected with VAW. Further studies exploring the EMS of the partner and how they are connected to the women's schemas would be a significant way to better assess the connection that combined this couple.

\section{Limitations}

This study also has some limitations. Since it is a cross-sectional study, it is not possible to establish the temporal sequence of events. In this light, we cannot understand whether the activation of the dysfunctional schemas is caused by a childhood event or by intimate partner violence alone. In addition, all evaluations were based on respondents' self-reports and are likely to be underestimated or overestimated which could lead to information bias. In addition, not all scales are validated among the Lebanese population.

\section{Conclusion}

This current research admit a positive correlation between violence against women and the activation of early maladaptive schemas. Because each individual is unique, it can be essential to evaluate the factor that can improve the dysfunctional schemas activation. Moreover, further study is required to better comprehend the schemes, their role in marriage dynamics in order to minimize their adverse effect as part of the treatment.

\section{Declarations}

\section{Ethics Approval and Consent to Participate}

The Psychiatric Hospital of the Cross Ethics and Research Committee approved this study protocol (reference number: HPC-004-2019). A written informed consent was obtained from each participant.

\section{Consent for publication}

Not applicable.

\section{Availability of data and materials}

All data generated or analyzed during this study are not publicly available to maintain the privacy of the individuals' identities. The dataset supporting the conclusions is available upon request to the corresponding author. 


\section{Competing interests}

The authors have nothing to disclose.

\section{Funding}

None.

\section{Author contributions}

$\mathrm{MA}, \mathrm{CK}, \mathrm{HO}$ and $\mathrm{CR}$ were responsible for the data collection and entry. SH and SO designed the study; CR drafted the manuscript; $\mathrm{SH}, \mathrm{SO}$ and $\mathrm{CH}$ carried out the analysis and interpreted the results; $\mathrm{CH}, \mathrm{CK}, \mathrm{MA}$ and $\mathrm{HO}$ assisted in drafting and reviewing the manuscript; All authors reviewed the final manuscript and gave their consent; $\mathrm{SO}$ and $\mathrm{SH}$ were the project supervisors.

\section{Acknowledgements}

Special thanks to all women who participated in this study.

\section{References}

1. Heise L. Violence against women: the missing agenda. In: The health of women. Routledge; 2018:171-196.

2. Alves MJV, Manita C, Caldas IM, Fernández-Martinez E, Gomes da Silva A, Magalhães T. Evolution and analysis of cultural and cognitive factors related with domestic violence against women. Journal of interpersonal violence. 2019;34(3):621-641.

3. World Health Organization. Violence against women. Available from: https://www.who.int/newsroom/fact-sheets/detail/violence-against-women. Published 2017. Accessed.

4. Navarro-Mantas L, Velásquez MJ, Lemus Sd, Megías JL. Prevalence and sociodemographic predictors of intimate partner violence against women in El Salvador. Journal of interpersonal violence. 2018:0886260518779065.

5. Khadra C, Wehbe N, Lachance Fiola J, Skaff W, Nehmé M. Symptoms of post-traumatic stress disorder among battered women in Lebanon: an exploratory study. Journal of interpersonal Violence. 2015;30(2):295-313.

6. Calvete E, Gámez-Guadix M, Fernández-Gonzalez L, Orue I, Borrajo E. Maladaptive schemas as mediators of the relationship between previous victimizations in the family and dating violence victimization in adolescents. Child abuse \& neglect. 2018;81:161-169.

7. Atmaca $S$, Gençöz T. Exploring revictimization process among Turkish women: The role of early maladaptive schemas on the link between child abuse and partner violence. Child abuse \& neglect. 2016;52:85-93. 
8. Falahatdoost M, Dolatshahi B, Mohammadkhani P, Nouri M. Identifying the role of early maladaptive schemas in variety of domestic violence against women with the experience of violence. Practice in Clinical Psychology. 2013;1(4):219-225.

9. Estévez A, Ozerinjauregi N, Herrero-Fernández D. Maladaptive schemas as mediators in the relationship between child sexual abuse and displaced aggression. Journal of child sexual abuse. 2016;25(4):449-465.

10. Pietri M, Bonnet A. Analysis of early representations and personality among victims of domestic violence. Revue Européenne de Psychologie Appliquée/European Review of Applied Psychology. 2017;67(4):199-206.

11. Obeid S, Hallit S. Correlation of the Stockholm syndrome and early maladaptive schemas among Lebanese women victims of beating into domestic/marital violence. Couple and Family Psychology: Research and Practice. 2018;7(3-4):171.

12. Gonzalez-Mendez R, Jiménez-Ardila O, Ramírez-Santana G. Ideal and actual partner assessments in male batterers with different attachment styles. PloS one. 2019;14(3):e0214388.

13. Grady MD, Yoder J, Brown A. Childhood maltreatment experiences, attachment, sexual offending: testing a theory. Journal of interpersonal violence. 2018:0886260518814262.

14. Jonker IE, Lako DA, Beijersbergen MD, Sijbrandij M, van Hemert AM, Wolf JR. Factors related to depression and post-traumatic stress disorder in shelter-based abused women. Violence against women. 2019;25(4):401-420.

15. Usta J, Farver JM, Hamieh CS. Effects of socialization on gender discrimination and violence against women in Lebanon. Violence against women. 2016;22(4):415-431.

16. Obeid N, Chang DF, Ginges J. Beliefs about wife beating: An exploratory study with Lebanese students. Violence against women. 2010;16(6):691-712.

17. www.cas.gov.lb TCAoSiLaf. Published 2019. Accessed.

18. Usta J, Farver JA, Pashayan N. Domestic violence: the Lebanese experience. Public Health. 2007;121(3):208-219.

19. Mengo C, Okumu M, Ombayo B, Nahar S, Small E. Marital Rape and HIV Risk in Uganda: The Impact of Women's Empowerment Factors. Violence against women. 2019:1077801218821444.

20. Tutty LM, Babins-Wagner RR, Rothery MA. You're not alone: Mental health outcomes in therapy groups for abused women. Journal of family violence. 2016;31(4):489-497.

21. Tutty LM, Babins-Wagner R, Rothery MA. Women in IPV treatment for abusers and women in IPV survivor groups: different or two sides of the same coin? Journal of family violence. 2017;32(8):787797.

22. Taebi M, Gandomani SJ, Nilforoushan P, GholamiDehaghi A. Association between infertility factors and non-physical partner abuse in infertile couples. Iranian journal of nursing and midwifery research. 2016;21(4):368. 
23. Mohammadkhani P, Mohammadi M, Nazari M, Salavati M, Razzaghi O. DEV ELOPMENT, VALIDATION AND RELIABILITY OF CHILD ABUSE SELF REPORT SCALE (CASRS) IN IRANIAN STUDENTS. Medical Journal of The Islamic Republic of Iran (MJIRI). 2003;17(1):51-58.

24. Hadianfard $\mathrm{H}$. Child abuse in group of children with attention deficit-hyperactivity disorder in comparison with normal children. Int J Community Based Nurs Midwifery. 2014;2(2):77-84.

25. Tryjarska B. Style przywiązania partnerów a tworzenie bliskich związków w dorosłości. Bliskość w rodzinie Więzi w dzieciństwie a zaburzenia w dorosłości Warszawa: Wydawnictwo Naukowe Scholar. 2012:185-217.

26. Kang S, Ndukwe N, Fassnacht D. The Relationship between Men's Early Maladaptive Schemas, Rape Myth Acceptance and Self-Reported Likelihood of Using Force and Raping. J Psychol Clin Psychiatry. 2016;6(6):00382.

27. Corral C, Calvete E. Early maladaptive schemas and personality disorder traits in perpetrators of intimate partner violence. The Spanish journal of psychology. 2014;17.

28. Begum S, Donta B, Nair S, Prakasam C. Socio-demographic factors associated with domestic violence in urban slums, Mumbai, Maharashtra, India. The Indian journal of medical research. 2015;141(6):783.

29. Shorey RC, Anderson S, Stuart GL. Early maladaptive schemas of substance abusers and their intimate partners. Journal of psychoactive drugs. 2013;45(3):266-275.

30. Shorey RC, Anderson SE, Stuart GL. Gender differences in early maladaptive schemas in a treatmentseeking sample of alcohol-dependent adults. Substance use \& misuse. 2012;47(1):108-116.

31. Adib-Hajbaghery M, Karimi R, Karbasi H, Haji-Rezaei M, Aminolroayaee E. Comparing violence against women with and without an addicted spouse in Kashan, Iran. Addiction \& health. 2015;7(12):74.

32. Smith LS, Stover CS. The moderating role of attachment on the relationship between history of trauma and intimate partner violence victimization. Violence against women. 2016;22(6):745-764.

33. Newark PE, Elsässer M, Stieglitz R-D. Self-esteem, self-efficacy, and resources in adults with ADHD. Journal of Attention Disorders. 2016;20(3):279-290.

34. Dekel R, Shaked O, Ben-Porat A, Itzhaky H. The interrelations of physical and mental health: self-rated health, depression, and PTSD among female IPV survivors. Violence against women. 2019:1077801219832916.

\section{Tables}


Table 1 : Sociodemographic characteristics of the sample population

\section{Education level}

Frequency

$\%$

\begin{tabular}{|c|c|c|}
\hline Illiterate & 92 & $5.6 \%$ \\
\hline Primary & 99 & $6.1 \%$ \\
\hline Complementary & 161 & $9.9 \%$ \\
\hline Secondary & 325 & $19.9 \%$ \\
\hline University & 956 & $58.5 \%$ \\
\hline \multicolumn{3}{|l|}{ Monthly income } \\
\hline Less than $1000 \$$ & 972 & $63.2 \%$ \\
\hline $1000-2000 \$$ & 441 & $28.7 \%$ \\
\hline More than $2000 \$$ & 125 & $8.1 \%$ \\
\hline \multicolumn{3}{|l|}{ Marital status } \\
\hline Single & 567 & $34.4 \%$ \\
\hline Married & 950 & $57.7 \%$ \\
\hline Widowed & 38 & $2.3 \%$ \\
\hline Divorced & 91 & $5.5 \%$ \\
\hline \multicolumn{3}{|l|}{ Social status } \\
\hline Non-employed/housewife & 526 & $32.5 \%$ \\
\hline Employed & 693 & $42.8 \%$ \\
\hline School or university student & 401 & $24.8 \%$ \\
\hline \multicolumn{3}{|l|}{ Religion } \\
\hline Christian & 167 & $10.2 \%$ \\
\hline Muslim & 1280 & $78.3 \%$ \\
\hline Druze & 162 & $9.9 \%$ \\
\hline Atheist & 25 & $1.5 \%$ \\
\hline \multicolumn{3}{|l|}{ Alcohol use } \\
\hline Yes & 328 & $19.8 \%$ \\
\hline No & 1327 & $80.2 \%$ \\
\hline \multicolumn{3}{|l|}{ Substance use } \\
\hline Yes & 60 & $3.6 \%$ \\
\hline \multirow[t]{2}{*}{ No } & 1595 & $96.4 \%$ \\
\hline & Mean & SD \\
\hline Age (in years) & 31.46 & 10.97 \\
\hline Number of kids & 2.72 & 1.53 \\
\hline
\end{tabular}


Table 2: Bivariable analysis taking the partner physical and non-physical abuse scales as the dependent variables

\begin{tabular}{|c|c|c|c|c|}
\hline & $\begin{array}{c}\text { Partner physical } \\
\text { abuse scale }\end{array}$ & p-value & $\begin{array}{c}\text { Partner } \\
\text { nonphysical } \\
\text { abuse scale } \\
\end{array}$ & p-value \\
\hline & Mean \pm SD & & Mean \pm SD & \\
\hline \multicolumn{5}{|l|}{ Education level } \\
\hline Illiterate & $63.99 \pm 40.68$ & \multirow[t]{5}{*}{$<0.001$} & $79.99 \pm 41.00$ & \multirow[t]{5}{*}{$<0.001$} \\
\hline Primary & $49.45 \pm 32.84$ & & $67.24 \pm 43.13$ & \\
\hline Complementary & $37.48 \pm 27.61$ & & $53.53 \pm 34.97$ & \\
\hline Secondary & $35.14 \pm 23.62$ & & $49.41 \pm 33.13$ & \\
\hline University & $34.45 \pm 22.26$ & & $44.74 \pm 28.17$ & \\
\hline \multicolumn{5}{|l|}{ Monthly income } \\
\hline Less than $1000 \$$ & $38.67 \pm 27.98$ & \multirow[t]{3}{*}{0.326} & $51.53 \pm 34.71$ & \multirow[t]{3}{*}{0.082} \\
\hline $1000-2000 \$$ & $36.01 \pm 24.03$ & & $46.80 \pm 30.55$ & \\
\hline More than $2000 \$$ & $34.23 \pm 21.64$ & & $50.10 \pm 31.58$ & \\
\hline \multicolumn{5}{|l|}{ Marital status } \\
\hline Single & $37.88 \pm 26.54$ & \multirow[t]{4}{*}{$<0.001$} & $45.04 \pm 28.95$ & \multirow[t]{4}{*}{$<0.001$} \\
\hline Married & $35.07 \pm 23.89$ & & $49.49 \pm 33.14$ & \\
\hline Widowed & $42.87 \pm 31.98$ & & $57.89 \pm 35.13$ & \\
\hline Divorced & $59.77 \pm 36.34$ & & $79.23 \pm 39.99$ & \\
\hline \multicolumn{5}{|l|}{ Social status } \\
\hline Non-employed/housewife & $39.23 \pm 28.60$ & \multirow[t]{3}{*}{0.014} & $55.21 \pm 36.46$ & \multirow[t]{3}{*}{$<0.001$} \\
\hline Employed & $36.54 \pm 25.16$ & & $48.99 \pm 32.83$ & \\
\hline School or university student & $36.66 \pm 24.94$ & & $44.69 \pm 28.30$ & \\
\hline \multicolumn{5}{|l|}{ Religion } \\
\hline Christian & $41.78 \pm 26.89$ & \multirow[t]{4}{*}{$<0.001$} & $56.81 \pm 36.81$ & \multirow[t]{4}{*}{$<0.001$} \\
\hline Muslim & $36.18 \pm 25.40$ & & $48.57 \pm 32.42$ & \\
\hline Druze & $39.93 \pm 28.45$ & & $52.16 \pm 32.95$ & \\
\hline Atheist & $74.83 \pm 36.71$ & & $83.57 \pm 38.77$ & \\
\hline \multicolumn{5}{|l|}{ Alcohol use } \\
\hline Yes & $45.24 \pm 30.63$ & \multirow[t]{2}{*}{$<0.001$} & $57.83 \pm 36.82$ & \multirow[t]{2}{*}{$<0.001$} \\
\hline No & $35.78 \pm 25.02$ & & $48.30 \pm 32.17$ & \\
\hline \multicolumn{5}{|l|}{ Substance use } \\
\hline Yes & $58.20 \pm 36.99$ & \multirow[t]{2}{*}{$<0.001$} & $73.89 \pm 41.17$ & \multirow[t]{2}{*}{$<0.001$} \\
\hline No & $36.87 \pm 25.70$ & & $49.29 \pm 32.70$ & \\
\hline \multicolumn{5}{|l|}{ Partner addicted to gambling } \\
\hline Yes & $76.38 \pm 32.82$ & \multirow[t]{2}{*}{$<0.001$} & $96.19 \pm 33.07$ & \multirow[t]{2}{*}{$<0.001$} \\
\hline No & $32.81 \pm 21.51$ & & $45.14 \pm 29.76$ & \\
\hline \multicolumn{5}{|c|}{ Partner have an history of threats, violence, assaults and crimes } \\
\hline Yes & $77.67 \pm 36.77$ & \multirow[t]{2}{*}{$<0.001$} & $97.65 \pm 41.23$ & \multirow[t]{2}{*}{$<0.001$} \\
\hline No & $32.25 \pm 20.24$ & & $44.30 \pm 28.37$ & \\
\hline Partner take substance & & & & \\
\hline Yes & $87.58 \pm 33.06$ & $<0.001$ & $106.96 \pm 40.22$ & $<0.001$ \\
\hline
\end{tabular}




\begin{tabular}{|c|c|c|c|c|}
\hline No & $32.73 \pm 21.12$ & & $45.32 \pm 29.08$ & \\
\hline \multicolumn{5}{|l|}{ Partner addicted to alcohol } \\
\hline Yes & $70.29 \pm 34.77$ & \multirow[t]{2}{*}{$<0.001$} & $92.30 \pm 41.99$ & \multirow[t]{2}{*}{$<0.001$} \\
\hline \multirow[t]{2}{*}{ No } & $32.80 \pm 21.17$ & & $45.08 \pm 28.76$ & \\
\hline & $\begin{array}{c}\text { Correlation } \\
\text { coefficient }\end{array}$ & p-value & $\begin{array}{c}\text { Correlation } \\
\text { coefficient }\end{array}$ & p-value \\
\hline Age & -0.019 & 0.462 & 0.055 & 0.031 \\
\hline $\begin{array}{l}\text { Stressful life experiences (PTSD - } \\
\text { Civilian scale (PCL-C) }\end{array}$ & 0.499 & $<0.001$ & 0.554 & $<0.001$ \\
\hline Child psychological abuse scale & 0.624 & $<0.001$ & 0.566 & $<0.001$ \\
\hline Child physical abuse scale & 0.686 & $<0.001$ & 0.582 & $<0.001$ \\
\hline Child neglect abuse scale & 0.376 & $<0.001$ & 0.331 & $<0.001$ \\
\hline Child sexual abuse scale & 0.688 & $<0.001$ & 0.523 & $<0.001$ \\
\hline $\begin{array}{l}\text { Young schema emotional } \\
\text { deprivation }\end{array}$ & 0.375 & $<0.001$ & 0.471 & $<0.001$ \\
\hline Young schema abandonment & 0.296 & $<0.001$ & 0.342 & $<0.001$ \\
\hline Young schema mistrust/abuse & 0.282 & $<0.001$ & 0.322 & $<0.001$ \\
\hline Young schema social isolation & 0.434 & $<0.001$ & 0.462 & $<0.001$ \\
\hline Young schema defectiveness & 0.454 & $<0.001$ & 0.455 & $<0.001$ \\
\hline Young schema failure & 0.369 & $<0.001$ & 0.394 & $<0.001$ \\
\hline Young schema dependence & 0.412 & $<0.001$ & 0.422 & $<0.001$ \\
\hline Young schema vulnerability & 0.291 & $<0.001$ & 0.347 & $<0.001$ \\
\hline Young schema enmeshment & 0.294 & $<0.001$ & 0.334 & $<0.001$ \\
\hline Young schema subjugation & 0.447 & $<0.001$ & 0.481 & $<0.001$ \\
\hline Young schema self-sacrifice & 0.076 & 0.003 & 0.162 & $<0.001$ \\
\hline Young schema emotional inhibition & 0.356 & $<0.001$ & 0.416 & $<0.001$ \\
\hline $\begin{array}{l}\text { Young schema unrelenting } \\
\text { standards }\end{array}$ & 0.014 & 0.578 & 0.077 & 0.002 \\
\hline Young schema entitlement & 0.069 & 0.007 & 0.127 & $<0.001$ \\
\hline Young schema approval seeking & 0.140 & $<0.001$ & 0.205 & $<0.001$ \\
\hline $\begin{array}{l}\text { Young schema } \\
\text { negativity/pessimism }\end{array}$ & 0.191 & $<0.001$ & 0.282 & $<0.001$ \\
\hline Young schema punitiveness & 0.163 & $<0.001$ & 0.200 & $<0.001$ \\
\hline $\begin{array}{l}\text { Relationship style A, } \\
\text { secured }\end{array}$ & -0.173 & $<0.001$ & -0.158 & $<0.001$ \\
\hline $\begin{array}{l}\text { Relationship style B, } \\
\text { preoccupied }\end{array}$ & 0.121 & $<0.001$ & 0.181 & $<0.001$ \\
\hline $\begin{array}{l}\text { Relationship style C, } \\
\text { fearful }\end{array}$ & 0.071 & 0.008 & 0.112 & $<0.001$ \\
\hline $\begin{array}{l}\text { Relationship style D, } \\
\text { dismissing }\end{array}$ & 0.001 & 0.969 & -0.028 & 0.298 \\
\hline
\end{tabular}




\section{Table 3: multivariable analysis}

Model 1: Linear regression taking the partner physical abuse scale variable as the dependent variable

\begin{tabular}{|c|c|c|c|c|c|}
\hline & \multirow[t]{2}{*}{$\begin{array}{l}\text { Unstandardized } \\
\text { Beta }\end{array}$} & \multirow[t]{2}{*}{\begin{tabular}{|c|} 
Standardized \\
Beta
\end{tabular}} & \multirow[t]{2}{*}{ p-value } & \multicolumn{2}{|c|}{$\begin{array}{l}\text { Confidence } \\
\text { interval }\end{array}$} \\
\hline & & & & $\begin{array}{l}\text { Lower } \\
\text { bound }\end{array}$ & $\begin{array}{l}\text { Upper } \\
\text { bound }\end{array}$ \\
\hline Child physical abuse scale & 1.581 & 0.257 & $<0.001$ & 1.242 & 1.920 \\
\hline Child sexual abuse scale & 3.770 & 0.316 & $<0.001$ & 3.212 & 4.329 \\
\hline $\begin{array}{l}\text { Child psychological abuse } \\
\text { scale }\end{array}$ & 0.258 & 0.073 & 0.007 & 0.071 & 0.446 \\
\hline $\begin{array}{l}\text { Stressful life experiences } \\
\text { (PTSD - Civilian scale } \\
\text { (PCL-C) }\end{array}$ & 0.240 & 0.118 & $<0.001$ & 0.152 & 0.328 \\
\hline Partner take substance & 9.641 & 0.065 & 0.001 & 3.710 & 15.571 \\
\hline Partner addicted alcohol & 5.033 & 0.047 & 0.015 & 0.967 & 9.100 \\
\hline $\begin{array}{l}\text { Partner addicted } \\
\text { gambling }\end{array}$ & 4.784 & 0.039 & 0.047 & 0.055 & 9.513 \\
\hline $\begin{array}{l}\text { Partner have an history } \\
\text { of threats, violence, } \\
\text { assaults and crimes }\end{array}$ & 8.458 & 0.069 & 0.001 & 3.687 & 13.229 \\
\hline Divorced & 12.116 & 0.111 & $<0.001$ & 8.484 & 15.747 \\
\hline University & -2.179 & -0.041 & 0.016 & -3.953 & -0.405 \\
\hline $\begin{array}{l}\text { Young schema } \\
\text { defectiveness }\end{array}$ & 0.459 & 0.075 & 0.017 & 0.081 & 0.837 \\
\hline $\begin{array}{l}\text { Young schema approval } \\
\text { seeking }\end{array}$ & 0.238 & 0.048 & 0.010 & 0.057 & 0.419 \\
\hline $\begin{array}{l}\text { Young schema social } \\
\text { isolation }\end{array}$ & 0.438 & 0.078 & 0.004 & 0.143 & 0.732 \\
\hline $\begin{array}{l}\text { Young schema emotional } \\
\text { deprivation }\end{array}$ & 0.427 & 0.078 & 0.002 & 0.162 & 0.692 \\
\hline $\begin{array}{l}\text { Young schema } \\
\text { subjugation }\end{array}$ & 0.310 & 0.055 & 0.039 & 0.016 & 0.603 \\
\hline Young schema failure & 0.521 & 0.084 & 0.003 & 0.173 & 0.869 \\
\hline $\begin{array}{l}\text { Young schema } \\
\text { dependence }\end{array}$ & 0.358 & 0.060 & 0.042 & 0.014 & 0.702 \\
\hline \multicolumn{6}{|c|}{$\begin{array}{l}\text { Model 2: Linear regression taking the partner nonphysical abuse scale variable as the } \\
\text { dependent variable }\end{array}$} \\
\hline & \multirow[t]{2}{*}{$\begin{array}{l}\text { Unstandardized } \\
\text { Beta }\end{array}$} & \multirow[t]{2}{*}{$\begin{array}{l}\text { Standardized } \\
\text { Beta }\end{array}$} & \multirow[t]{2}{*}{ p-value } & \multicolumn{2}{|c|}{$\begin{array}{l}\text { Confidence } \\
\text { interval }\end{array}$} \\
\hline & & & & $\begin{array}{l}\text { Lower } \\
\text { bound }\end{array}$ & $\begin{array}{l}\text { Upper } \\
\text { bound }\end{array}$ \\
\hline & & & & & \\
\hline
\end{tabular}




\begin{tabular}{|l|c|c|c|c|c|} 
Child physical abuse scale & 1.415 & 0.185 & $<0.001$ & 0.941 & 1.889 \\
\hline Child sexual abuse scale & 1.845 & 0.125 & $<0.001$ & 1.073 & 2.617 \\
\hline $\begin{array}{l}\text { Child psychological abuse } \\
\text { scale }\end{array}$ & 0.405 & 0.093 & 0.002 & 0.143 & 0.667 \\
\hline $\begin{array}{l}\text { Stressful life experiences } \\
\text { (PTSD - Civilian scale } \\
\text { (PCL-C) }\end{array}$ & 0.520 & 0.206 & $<0.001$ & 0.398 & 0.641 \\
\hline Partner addicted alcohol & 12.267 & 0.093 & $<0.001$ & 6.887 & 17.647 \\
\hline $\begin{array}{l}\text { Partner addicted } \\
\text { gambling }\end{array}$ & 9.321 & 0.061 & 0.005 & 2.772 & 15.871 \\
\hline $\begin{array}{l}\text { Partner have an history } \\
\text { of threats, violence, } \\
\text { assaults and crimes }\end{array}$ & 9.717 & 0.064 & 0.003 & 3.254 & 16.180 \\
\hline Married & 6.105 & 0.091 & $<0.001$ & 3.398 & 8.812 \\
\hline Divorced & 19.683 & 0.145 & $<0.001$ & 14.297 & 25.070 \\
\hline Widowed & 9.262 & 0.046 & 0.017 & 1.673 & 16.851 \\
\hline University & -3.938 & -0.059 & 0.002 & -6.473 & -1.404 \\
\hline $\begin{array}{l}\text { Relationship style B, } \\
\text { preoccupied }\end{array}$ & 0.926 & 0.055 & 0.004 & 0.299 & 1.553 \\
\hline $\begin{array}{l}\text { Young schema social } \\
\text { isolation }\end{array}$ & 0.446 & 0.064 & 0.023 & 0.062 & 0.831 \\
\hline $\begin{array}{l}\text { Young schema } \\
\text { subjugation }\end{array}$ & 0.596 & 0.085 & 0.002 & 0.228 & 0.965 \\
\hline $\begin{array}{l}\text { Young schema } \\
\text { unrelenting standards }\end{array}$ & 0.273 & 0.043 & 0.026 & 0.033 & 0.512 \\
\hline $\begin{array}{l}\text { Young Schema emotional } \\
\text { deprivation }\end{array}$ & 0.389 & 0.057 & 0.037 & 0.024 & 0.754 \\
\hline
\end{tabular}

